\title{
Impaired Skin Fibroblast Carnitine Uptake in Primary Systemic Carnitine Deficiency Manifested by Childhood Carnitine-Responsive Cardiomyopathy
}

\author{
I. TEIN, D. C. DE VIVO, F. BIERMAN, P. PUlVER, L. J. DE MEIRlEIR, L. CVITANOVIC-
} SOJAT, R. A. PAGON, E. BERTINI, C. DIONISI-VICI, S. SERVIDEI, AND S. DIMAURO

H. Houston Merritt Clinical Research Center for Muscular Dystrophy and Related Diseases [S.D.], The Division of Pediatric Neurology [I.T., D.C.D.V., P.P.], and The Division of Pediatric Cardiology [F. B.], Columbia University, New York, New York 10032; Department of Pediatric Neurology, Academisch Ziekenhuis, Vrije Universiteit Brussel, Brussels, Belgium [L.J.D.M.]; Clinique de Pediatrie, Hosp. Clin. Dr. M. Stojanovic, Zagreb, Yugoslavia [L.C.-S.]; Children's Hospital and Medical Center, University of Washington, Seattle, Washington 98105 [R.A.P.]; Departments of Metabolism and Cardiology, Bambino Gesu Pediatric Hospital, Rome, Italy [E.B., C.D.-V.]; and Institute of Neurology, Catholic University of Rome, Rome, Italy [S.S.]

\begin{abstract}
Evidence is emerging that primary systemic carnitine deficiency, a potentially lethal but eminently treatable inborn error of fatty acid oxidation, involves a cellular defect in the uptake of carnitine. We present four unrelated children with primary carnitine-responsive cardiomyopathy, weakness (with or without hypoketotic hypoglycemic encephalopathy), low serum and/or tissue carnitine concentrations, and severe renal carnitine leak. Dicarboxylic acids were absent in the urine of three children who were tested, and all four had a rapid and dramatic improvement in cardiac function, strength, and somatic growth after carnitine therapy. We studied carnitine uptake in cultured skin fibroblasts from all four children and seven of the eight healthy nonconsanguinous parents. $\left[{ }^{3} \mathrm{H}\right] \mathrm{L}$-carnitine uptake was evaluated in vitro under linear time kinetics. Substrate concentrations were varied from 0.1 to $1000 \mu \mathrm{M}$. Physiologic uptake was determined at carnitine concentrations between 0.1 and $50 \mu \mathrm{M}$. Nonspecific uptake was determined at a concentration of $10 \mathrm{mM}$. The four patients had negligible uptake throughout the physiologic range, implying a marked deficiency in the specific highaffinity, low-concentration, carrier-mediated uptake mechanism. At a concentration of $5 \mu \mathrm{mol} / \mathrm{L}$, the mean velocity of uptake in the four patients was $2 \%$ of control values. Their parents showed intermediate maximal rates of carnitine uptake ranging from 13 to $44 \%$ of control $V_{\max }$ values, but normal $\mathrm{Km}$ values, suggesting that the heterozygotes had a reduced number of normal functioning carnitine transporters. The observed reduction in $V_{\max }$ values for the parents supports an autosomal recessive inheritance pattern and may be a more sensitive indicator of heterozygosity than serum carnitine concentrations. We conclude that carnitine uptake studies in cultured skin fibroblasts are important for diagnosis, screening of siblings and heterozygote parents, understanding pathogenesis, and investigating the molecular basis of this disease. Given the
\end{abstract}

Received March 14, 1990; accepted May 1, 1990.

Correspondence and reprint requests: Dr. S. DiMauro, Department of Neurology, Rm. 4-420, College of Physicians and Surgeons, Columbia University, 630 West 168th Street, New York, NY 10032.

Supported by Center grants NS1 1766 from the National Institute of Neurological and Communicative Disorders and Stroke, the Muscular Dystrophy Association, and the Colleen Giblin Foundation for Pediatric Neurological Research. I.T. is a recipient of the Duncan L. Gordon Fellowship from the Toronto Hospital for Sick Children Foundation. frequent history of previously unexplained sibling deaths in these familes, early identification of presymptomatic siblings and oral institution of carnitine prophylaxis may decrease immediate and long-term morbidity and mortality. (Pediatr Res 28: 247-255, 1990)

Abbreviations

CK, creatine kinase

IQ, intelligence quotient

MCAD, medium-chain acyl CoA dehydrogenase $\mathrm{RBC}$, red blood cell

Carnitine ( $\beta$-hydroxy- $\gamma$-trimethylaminobutyric acid), a quaternary amine, has several important intracellular functions. 1 ) It serves as an essential cofactor for mitochondrial fatty acid oxidation by transferring long-chain fatty acids as acylcarnitine esters across the inner mitochondrial membrane. 2) It facilitates branched-chain $\alpha$-keto acid oxidation. 3) It shuttles acyl moieties chain-shortened by $\beta$-oxidation out of peroxisomes in the liver. 4) It modulates the intramitochondrial acyl $\mathrm{CoA} / \mathrm{CoA}$ sulfhydryl ratio in mammalian cells. Carnitine also has a detoxifying role of trapping potentially toxic acyl $\mathrm{CoA}$ metabolites that may increase during acute metabolic crises. Bremer (1) provides a synopsis of references for the potential roles of carnitine.

A major difficulty in assessing the role of carnitine deficiency in both genetic and acquired defects of fatty acid oxidation in childhood is that only a few disorders have been unequivocally attributed to primary carnitine deficiency.

Since 1973 (2), many patients with carnitine deficiency have been described, and they have been divided into two groups. Those with "systemic carnitine deficiency" had recurrent episodes of hypoglycemic, hypoketotic encephalopathy or "Reyelike" syndrome beginning in infancy or early childhood and low concentrations of carnitine in serum, muscle, and liver. Patients with "myopathic carnitine deficiency" had progressive lipid storage myopathy beginning in childhood or later in life, and carnitine deficiency was confined to skeletal muscle (3-5). However, recently, it has become apparent that many of these cases were, in fact, due to a variety of defects involving $\beta$-oxidation or the respiratory chain with secondary carnitine deficiency (6). For 
example, many patients initially diagnosed to have systemic carnitine deficiency were found to have MCAD deficiency ( 7 , 8). A common feature of genetic defects associated with secondary carnitine deficiency is an intramitochondrial block of oxidation of one or more of the acyl CoA compounds that can be esterified to carnitine. These defects (6) include specific inborn errors of fatty acid or amino acid oxidation, such as MCAD, long-chain acyl CoA dehydrogenase, short-chain acyl CoA dehydrogenase, and multiple acyl $\mathrm{CoA}$ dehydrogenase deficiencies, isovaleric acidemia, propionic acidemia, methyl malonic aciduria, $\beta$-hydroxy- $\beta$-methylglutaryl CoA lyase deficiency, and glutaryl $\mathrm{CoA}$ dehydrogenase deficiency. Although information on the tissue carnitine concentrations is not complete for all of these disorders, most seem to share the abnormalities seen in MCAD deficiency, namely low plasma concentrations of total carnitine, increased ratio of esterified carnitine/total carnitine, and low tissue concentrations of total carnitine. Similarly, certain patients with adult onset chronic weakness formerly diagnosed to be primary muscle carnitine deficiency have now been diagnosed to have other defects such as short-chain acyl CoA dehydrogenase deficiency $(9,10)$. A further important and still controversial issue in these cases of secondary carnitine deficiency is the degree to which carnitine therapy is beneficial in either acute or chronic situations (6).

Therefore, a definition of primary carnitine deficiency should be based on the following criteria: 1 ) the metabolic disorder is caused directly by inadequate carnitine; 2) it is accompanied by impaired fatty acid oxidation; 3) it is corrected when carnitine concentrations are restored to normal; and 4 ) it is not secondary to a defect of mitochondrial $\beta$-oxidation.

Possible causes of primary carnitine deficiency include: 1 ) defective biosynthesis and dietary intake; 2) defective intestinal absorption; 3) defective transport affecting uptake and/or release of carnitine from tissues; 4) renal loss due to decreased tubular reabsorption or increased excretion; and 5) increased degradation. No evidence for defective carnitine biosynthesis (11), defective absorption, or excessive degradation (12) was found in several patients with systemic carnitine deficiency, all of whom, however, were identified subsequently to have MCAD deficiency.

Evidence for a defect in cellular carnitine uptake was first offered in $1988(13,14)$. Eriksson et al. (13) documented carnitine deficiency in cultured fibroblasts from a 4-y-old girl with cardiomyopathy and found intermediate carnitine concentrations in the fibroblasts of the asymptomatic mother. Carnitine transport was studied directly by Treem et al. (14) in fibroblasts from an infant girl with hypoketotic, hypoglycemic coma, markedly decreased carnitine concentrations in plasma, liver, and muscle, and normal acyl CoA dehydrogenase activities. Carnitine administration corrected the defect in fasting ketogenesis and restored normal carnitine concentrations in plasma and liver, but not in muscle.

We have studied four unrelated patients with primary carnitine-responsive cardiomyopathy. Studies of carnitine uptake in cultured fibroblasts indicate that a defect in carnitine transport is the cause of carnitine deficiency in these children. We also found defective carnitine uptake in fibroblasts from the presumed heterozogyte parents of these patients, suggesting autosomal-recessive inheritance.

\section{CASE REPORTS}

Case 1. A 91/2-y-old girl was born of unrelated asymptomatic parents of East Indian and Caucasian heritage. A sister had congenital hypotonia and muscle atrophy, progressive cardiomyopathy with severe mitral regurgitation diagnosed at $1 \mathrm{y}$, failure to thrive, and progressive motor deterioration. She died at 3 y 5 mo of age and had fatty infiltration of the liver at autopsy.

The index patient was born a footling breech. A cardiac murmur was first noted at 1 mo of age. By 14 mo, her gross motor milestones plateaued, and over the next $2 \mathrm{y}$, she developed slowly progressive weakness and recurrent respiratory infections (Table 1). At 3 y of age, the patient's clinical findings included congestive heart failure with moderate-to-severe mitral regurgitation. Marked left ventricular dilatation was present on cardiac ultrasound examination. The ECG demonstrated peaked $T$ waves in the anterolateral precordial leads. She was started on digoxin and diuretics. At 4 y 3 mo of age, she was found to have very low carnitine concentrations in serum and muscle (Table 2 ). A muscle biopsy showed lipid storage, but $\beta$-oxidation enzymes were normal. Serum CK was mildly elevated. Serum glucose was normal, as were urinary organic acids. There was no dicarboxylic aciduria. Oral carnitine was started at $1 \mathrm{~g} 3$ times daily. In $1 \mathrm{wk}$, there was a dramatic improvement in appetite and affect and cardiac function (Fig. 1). By 4 wk, she had gained weight and markedly increased exercise tolerance, and the ECG showed inversion of the formerly peaked $\mathrm{T}$ waves. By $4 \mathrm{mo}$, she had good exercise tolerance and cardiac end diastolic and end systolic dimensions had markedly improved (Fig. 1). At $5 \mathrm{y}$ of age, she had regained gross motor milestones. Her digoxin and diuretics were discontinued by $6^{1 / 2}$ y. Presently, at 9 y of age, she has an IQ of 140 and is a competitive swimmer at school. On examination, she has a mildly myopathic facies, mild hypotonia absent extensor digitorum brevis bilaterally, and persistent, although improving, fine motor delay. Electromyogram was normal. Motor nerve conduction studies revealed borderline abnormalities. Her serum carnitine concentrations fluctuate between borderline and normal, and she continues to have decreased renal reabsorption of carnitine. Her father's serum carnitine concentrations are normal (total 60.9 , free $54.7 \mu \mathrm{mol} / \mathrm{L}$ ), and her mother's are low normal (total 35.7, free $27.8 \mu \mathrm{mol} / \mathrm{L}$ ).

Case 2. A 10-y-old Italian boy was born of nonconsanguinous parents. At 17 mo of age, he had gross motor delay and failure to thrive, and at 18 mo he began having recurrent episodes of abdominal pain and diarrhea for which cow's milk protein intolerance was excluded (Table 1). At $7 \frac{1}{2} \mathrm{y}$, he was found to have a dilatative cardiomyopathy by chest $x$-ray and echocardiography with peaked $\mathrm{T}$ waves on ECG. He had marked hypochromic anemia requiring blood transfusions, and decreased serum iron of $25 \mu \mathrm{g} / \mathrm{dL}$ (normal 50-120). Thalassemia was ruled out. He also had weakness of neck flexor and limb-girdle muscles. He had an IQ of 67 and failure to thrive. He had low carnitine concentrations in serum and muscle (Table 2), as well as a striking decrease in renal reabsorption of carnitine (52\%; normal $>95 \%$ ) despite low serum concentrations. Both parents had low serum carnitine concentrations (father: total 35 , free $24 \mu \mathrm{mol} / \mathrm{L}$; mother: total 21 , free $14 \mu \mathrm{mol} / \mathrm{L}$; control: total $45 \pm 6.5$, free 34 $\pm 8.8 \mu \mathrm{mol} / \mathrm{L})$. Serum glucose and CK and urinary organic acid

Table 1. Major clinical and laboratory features-CPMC series*

\begin{tabular}{|c|c|c|c|c|c|c|c|c|c|c|c|c|c|}
\hline Patien & Sex & $\begin{array}{l}\text { Age of } \\
\text { onset } \\
\text { (mo) }\end{array}$ & $\begin{array}{c}\text { Presenting } \\
\text { feature }\end{array}$ & $\begin{array}{l}\text { Affected } \\
\text { siblings }\end{array}$ & $\begin{array}{l}\text { Cardio- } \\
\text { myopathy }\end{array}$ & $\begin{array}{l}\text { Weakness or } \\
\text { motor delay }\end{array}$ & $\begin{array}{c}\text { Lipid storage } \\
\text { in muscle }\end{array}$ & Coma & $\begin{array}{c}\text { Decrease in } \\
\text { fasting keto- } \\
\text { genesis }\end{array}$ & FTT & Anemia & $\begin{array}{l}\text { Decrease in } \\
\text { renal reab- } \\
\text { sorption }\end{array}$ & $\begin{array}{c}\text { Dicarboxylic } \\
\text { aciduria }\end{array}$ \\
\hline 1 & $\mathrm{~F}$ & 1 & Cardiac & + & + & + & + & - & ND & + & + & + & - \\
\hline 2 & $\mathrm{M}$ & 17 & Motor delay & - & + & + & + & - & ND & + & + & + & - \\
\hline 3 & $\mathrm{~F}$ & 1 & Hypotonia & - & + & + & ND & + & + & - & - & + & - \\
\hline 4 & $\mathrm{~F}$ & 2 & Cardiac & + & + & + & + & $+?$ & $+?$ & + & + & NR & NR \\
\hline
\end{tabular}

* CPMC, Columbia-Presbyterian Medical Center; FTT, failure to thrive; ND, not done; NR, not recorded. 
Table 2. Response to carnitine therapy-CPMC series*

\begin{tabular}{|c|c|c|c|c|c|c|c|c|c|c|c|}
\hline \multirow[b]{2}{*}{ Patient } & \multicolumn{2}{|c|}{$\begin{array}{l}\text { Serum carnitine total/free } \\
\qquad(\mu \mathrm{mol} / \mathrm{L})\end{array}$} & \multicolumn{2}{|c|}{$\begin{array}{l}\text { Muscle carnitine } \\
\text { total/free }(\mu \mathrm{mol} / \mathrm{g})\end{array}$} & \multicolumn{2}{|c|}{ Wt (percentile) } & \multicolumn{2}{|c|}{ Anemia $(\mathrm{Hb} \mathrm{g} / \mathrm{dL})$} & \multicolumn{3}{|c|}{ Improved function } \\
\hline & Before & After & Before & After & Before & After & Before & After & Motor & Cardiac & Cognitive \\
\hline 1 & $19 / 15 \dagger$ & $25-60 / 17-33 \ddagger$ & $0.17 / 0.11 \S$ & ND & 3 & 50 & 10.2 & 12.2 & + & + & + \\
\hline 2 & $1.2 / 1.2 \|$ & $9-28 / 9-17 \pi$ & $1.1^{* *}$ & $2.7 \dagger \dagger$ & 3 & 50 & 5 & $7.1-11.8$ & + & + & - \\
\hline 3 & 0 & & ND & ND & & 抹 & NR & NR & + & + & NR \\
\hline 4 & $9 / 5 \S \S$ & & $0.97^{* *}$ & ND & $<20$ & \|\| & Hct $28 \%$ & Het $38 \%$ & + & + & + \\
\hline
\end{tabular}

* CPMC, Columbia-Presbyterian Medical Center; NCP, noncollagen protein; ND, not done; NR, not recorded.

$\dagger$ Normal control values: $51.5 \pm 11.6 / 40.0 \pm 9.5 \mu \mathrm{mol} / \mathrm{L}$.

$\ddagger 1$ wk later.

$\S$ Normal control values: $3.61 / 2.69 \pm 0.56 \mu \mathrm{mol} / \mathrm{g}$ wet wt.

|l Normal control values: $45 \pm 6.5 / 34 \pm 8.8 \mu \mathrm{mol} / \mathrm{L}$.

II $1-2$ y later.

** Normal control values: $20.5 \pm 8.7 / 18.0 \pm 8.1 \mu \mathrm{mol} / \mathrm{g} \mathrm{NCP}$.

+1 y later.

\$ Wt increased; percentile not determined.

$\S \S$ Normal control values: $35-56 / 29-45 \mu \mathrm{mol} / \mathrm{L}$.

\|\| $\mathrm{Wt}$ increased $1.5 \mathrm{~kg}$ after $5 / 12 \mathrm{y}$; percentile not determined.

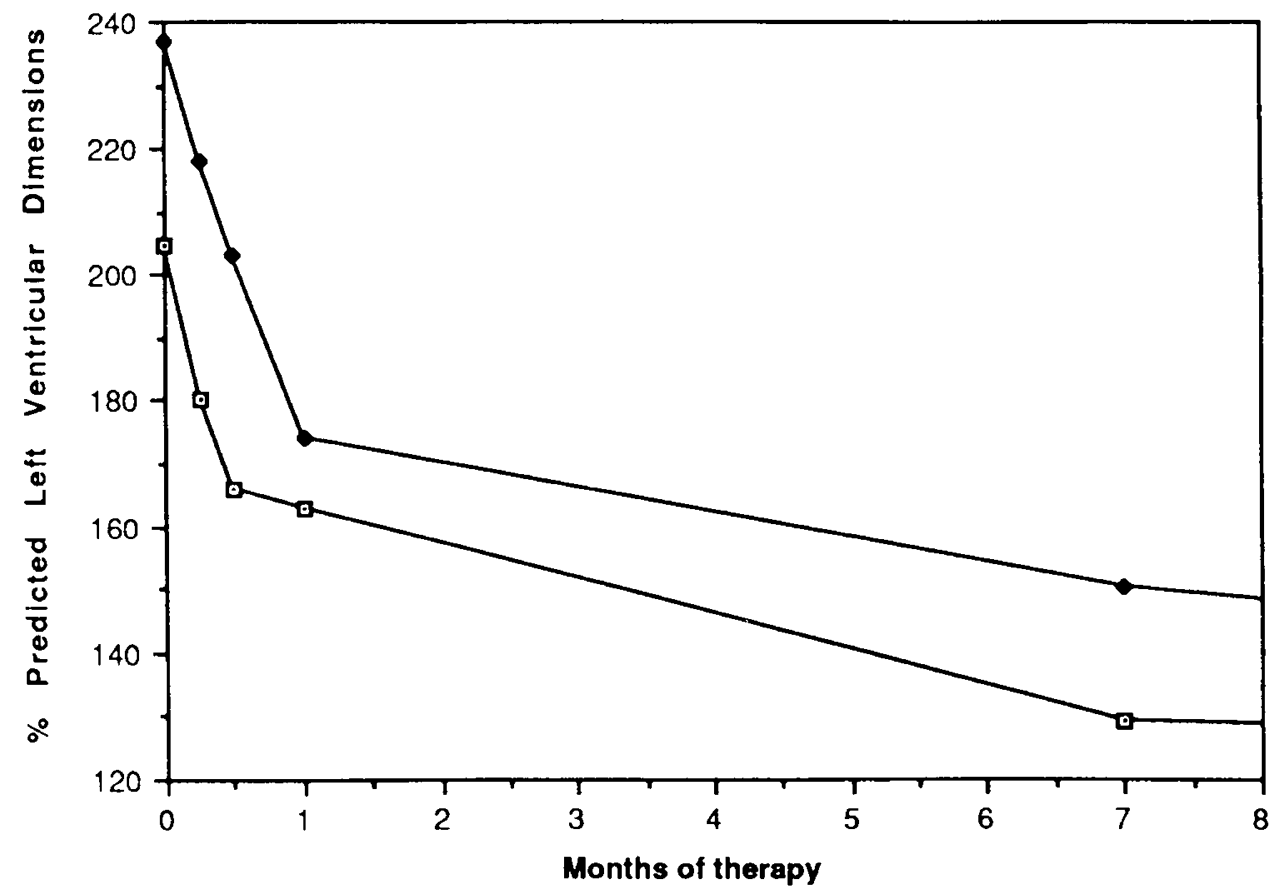

Fig. 1. Left ventricular dimensions in patient 1. Longitudinal follow-up of ratio between actual and percent predicted left ventricular end diastolic $(\square)$ and end systolic $(\$)$ dimensions after initiation of carnitine therapy. Accelerated response evident during 1 st mo of therapy persists toward a plateau by 8 mo of treatment.

profile were normal. Muscle biopsy showed lipid storage myopathy with normal mitochondria. He was started on oral carnitine therapy $(150 \mathrm{mg} / \mathrm{kg} / \mathrm{d})$ and digoxin, and his heart rate dropped from 120 to 80 beats per min in a few days. There was a gradual improvement of cardiac function and the ECG normalized in 2 $\mathrm{y}$. The patient regained normal strength and weight in $1 \mathrm{y}$ and the recurrent abdominal pains subsided. He continued to have hypochromic anemia with $\mathrm{Hb}$ levels between 7 and $12 \mathrm{~g} / \mathrm{dL}$. A repeat IQ was 75. By 9 y of age, he had shown significant clinical improvement, and a second muscle biopsy showed no lipid accumulation despite persistently low serum and muscle carnitine concentrations (Table 2).

Case 3. A $4 \frac{1}{2} 2$-y-old girl of Yugoslovian origin born of healthy nonconsanguinous parents had normal early growth but was always hypotonic. At $2 \frac{1 / 2}{2}$, during an episode of pharyngitis, she became flaccid and somnolent and, on hospitalization, was found to have hypoglycemia ( $1 \mathrm{mmol} / \mathrm{L})$, elevated serum glutamicoxaloacetic transaminase, and normal ammonia. An EEG re- vealed large amplitude slow waves. She returned to normal and had normal serum glucose after $24 \mathrm{~h}$; the serum glutamicoxaloacetic transaminase and EEG normalized after $1 \mathrm{wk}$. She experienced similar episodes at 3 and $3 \frac{1}{2}$ y of age, coinciding with viral infections and fever and accompanied by nonketotic hypoglycemia, elevation of total serum lipoproteins, and increased CK $(1280 \mathrm{U} / \mathrm{L}$; normal <150). Serum and urine amino acids and serum lactate and pyruvate were normal. An oral glucose tolerance test after insulin and glucagon challenges was normal. Echocardiogram revealed a cardiomyopathy. A 24-h fasting test resulted in marked hypoglycemia and somnolence that lasted $3 \mathrm{~d}$ despite glucose infusion. Total serum lipoproteins were again elevated and CK was slightly raised. During a separate 17-h fast, urine organic acids were normal. Free carnitine in the blood was undetectable in the presence of high urinary acyl carnitine, suggesting a renal carnitine leak. Oral carnitine therapy resulted in marked improvement of cardiac function with normal echocardiogram and ECG, increased strength, and improved appetite and growth. 
A

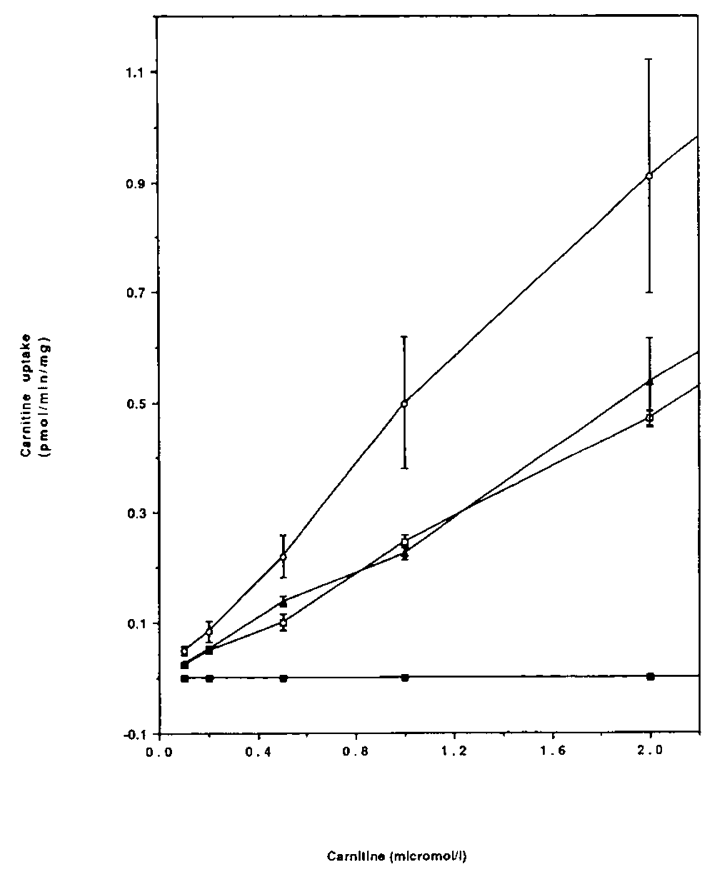

B

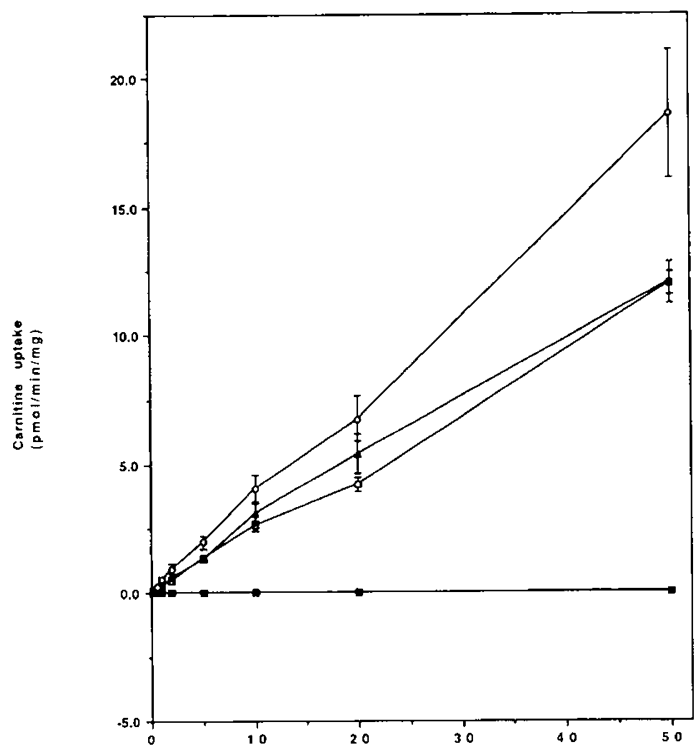

Carnilino (mleromolli)

Fig. 2. Carnitine uptake studies. Mean $( \pm$ SEM) rates of carnitine uptake by cultured skin fibroblasts from patient $1(\square)$, mother of patient $1(\square)$, father of patientl $(\mathbf{\Lambda})$, and six controls $(\bigcirc)$. The data represent two separate experiments (each performed in duplicate) in the patient and her parents and three to four separate experiments (each performed in duplicate) in each control. $a$, rates of uptake with extracellular carnitine concentrations ranging from 0.1 to $2.0 \mu \mathrm{mol} / \mathrm{L} . b$, rates of uptake with extracellular carnitine concentrations ranging from 1.0 to $50 \mu \mathrm{mol} / \mathrm{L}$.

Table 3. Carnitine uptake in cultured fibroblasts

\begin{tabular}{|c|c|c|c|c|c|c|}
\hline \multirow[b]{2}{*}{$\begin{array}{l}\text { Normal controls } \\
\qquad(n=6 ; 3 \text { female, } 3 \text { male })\end{array}$} & \multicolumn{2}{|c|}{$\begin{array}{c}\mathrm{Km} \\
\left(10^{-6} \mathrm{~mol} / \mathrm{L}\right)\end{array}$} & \multicolumn{2}{|c|}{$\begin{array}{c}\mathrm{V}_{\max } \text { uptake } \\
\left(10^{-12} \mathrm{~mol} / \mathrm{min} / \mathrm{mg}\right)\end{array}$} & \multicolumn{2}{|c|}{$\begin{array}{l}\% \text { Control } \\
\mathrm{V}_{\max }\end{array}$} \\
\hline & \multicolumn{2}{|c|}{$5.5 \pm 0.58^{*}$} & \multicolumn{2}{|c|}{$3.4 \pm 0.36^{*}$} & \multicolumn{2}{|c|}{100} \\
\hline \multicolumn{7}{|l|}{ Disease controls } \\
\hline $\begin{array}{l}\text { Carnitine palmitoyl transferase de- } \\
\text { ficiency }\end{array}$ & \multicolumn{2}{|c|}{5.0} & \multicolumn{2}{|c|}{3.33} & \multicolumn{2}{|c|}{100} \\
\hline Methylmalonic acidemia & \multicolumn{2}{|c|}{5.0} & \multicolumn{2}{|c|}{1.67} & \multicolumn{2}{|c|}{50} \\
\hline Hyperinsulinism & \multirow{2}{*}{\multicolumn{2}{|c|}{$\begin{array}{l}6.6 \\
6.6\end{array}$}} & \multirow{2}{*}{\multicolumn{2}{|c|}{$\begin{array}{l}3.00 \\
2.00\end{array}$}} & \multirow{2}{*}{\multicolumn{2}{|c|}{$\begin{array}{l}88 \\
59\end{array}$}} \\
\hline Primary cardiomyopathy & & & & & & \\
\hline Parents & Mother & Father & Mother & Father & Mother & Father \\
\hline Case 1 & 5.0 & 5.0 & 1.33 & 1.33 & 40 & 40 \\
\hline Case 2 & 5.0 & 5.0 & 1.50 & 0.44 & 44 & 13 \\
\hline Case 3 & 5.8 & 5.8 & 1.33 & 0.75 & 40 & 22 \\
\hline Case 4 & 5.7 & & 0.57 & & 17 & \\
\hline
\end{tabular}

$*$ Mean $\pm \mathrm{SD}$.

Table 4. Major clinical features-literature series

\begin{tabular}{|c|c|c|c|c|c|c|c|c|c|}
\hline Reference & Sex & $\begin{array}{c}\text { Af- } \\
\text { fected } \\
\text { siblings } \\
(n)\end{array}$ & Consanguinity & $\begin{array}{l}\text { Age at } \\
\text { onset } \\
\text { (mo) }\end{array}$ & $\begin{array}{l}\text { Presenting } \\
\text { feature }\end{array}$ & $\begin{array}{l}\text { Cardio- } \\
\text { myopathy }\end{array}$ & $\begin{array}{l}\text { Weakness or } \\
\text { motor delay }\end{array}$ & Coma/seizure & Hepatomegaly \\
\hline Chapoy et al. (19) 1980 & $M$ & $+(1)$ & - & 3 & Coma + cardiac & + & + & $+/+$ & + \\
\hline \multicolumn{10}{|l|}{ Tripp et al. (20) 1981} \\
\hline Case 1 & $\mathrm{~F}$ & $+(3)$ & - & 11 & Cardiac & + & - & & $-(+$ sibs $)$ \\
\hline Case 2 & M & $+(3)$ & - & 26 & Cardiac & + & & & + \\
\hline Waber et al. (21) 1982 & M & $+(1)$ & + & 40 & Cardiac & + & + & & + \\
\hline \multicolumn{10}{|l|}{ Eriksson et al. (13) 1988} \\
\hline Case 1 & $\mathrm{~F}$ & $+(1)$ & & $<48$ & Cardiac & + & & & \\
\hline Case 2 & M & $+(1)$ & & $<18$ & Cardiac & + & & & \\
\hline Treem et al. (14) 1988 & $\mathrm{~F}$ & & & 3.5 & Coma & + & & $+/+$ & + \\
\hline
\end{tabular}


Table 5. Laboratory features and response to carnitine therapy-literature series

\begin{tabular}{|c|c|c|c|c|c|c|c|c|c|c|c|c|c|c|c|c|c|}
\hline \multirow[b]{2}{*}{ Reference } & \multirow[b]{2}{*}{ Sex } & \multirow[b]{2}{*}{$\begin{array}{l}\Downarrow \\
\text { Blood } \\
\text { sugar }\end{array}$} & \multirow[b]{2}{*}{$\begin{array}{c}\Downarrow \\
\text { Fasting } \\
\text { keto- } \\
\text { genesis }\end{array}$} & \multirow[b]{2}{*}{$\begin{array}{c}\text { Dicar- } \\
\text { boxylic- } \\
\text { aciduria }\end{array}$} & \multirow[b]{2}{*}{ Anemia } & \multirow[b]{2}{*}{$\begin{array}{l}\text { Plasma } \\
\text { carnitine } \\
\mu \mathrm{M} \text { total } \\
\text { (free) }\end{array}$} & \multicolumn{3}{|c|}{$\begin{array}{c}\% \text { Normal tissue } \\
\text { carnitine }\end{array}$} & \multirow[b]{2}{*}{$\begin{array}{l}\text { Lipid } \\
\text { storage } \\
\text { in } \\
\text { muscle }\end{array}$} & \multirow[b]{2}{*}{$\begin{array}{l}\text { Lipid } \\
\text { storage } \\
\text { in liver } \\
\end{array}$} & \multirow[b]{2}{*}{$\begin{array}{c}\Downarrow \\
\text { Renal } \\
\% \text { reab- } \\
\text { sorption }\end{array}$} & \multicolumn{5}{|c|}{ Beneficial response to carnitine therapy } \\
\hline & & & & & & & Muscle & Liver & Heart & & & & $\begin{array}{c}\% \\
\text { Normal } \\
\text { muscle } \\
\text { carnitine } \\
\end{array}$ & $\begin{array}{c}\text { Plasma } \\
\text { carnitine } \mu \mathrm{M} \\
\text { total (free) } \\
\end{array}$ & Muscle & Cardiac & $\begin{array}{l}\text { Keto- } \\
\text { genesis }\end{array}$ \\
\hline $\begin{array}{r}\text { Chapoy et al. } \\
\text { (19) } 1980\end{array}$ & M & + & + & - & & $4.8^{*}$ & 1.5 & 6 & & + & + & & 40 & 18 & + & + & \\
\hline $\begin{array}{l}\text { Tripp et al. } \\
\text { (20) } 1981\end{array}$ & & & & & & & & & & & & & & & & & \\
\hline Case 1 & $\mathrm{~F}$ & - & & & + & $4.8(3.6) \dagger$ & 1 & & & + & & & 5 & $13-44(12-36)$ & + & + & \\
\hline Case 2 & M & & & & + & $4.5(3.5) \dagger$ & 1 & 30 & 5 & & + & & & & & & \\
\hline $\begin{array}{l}\text { Waber et al. } \\
\text { (21) } 1982\end{array}$ & M & - & - & - & + & $4.2 \ddagger$ & 2 & & & + & & + & & $22-55$ & + & + & \\
\hline $\begin{array}{r}\text { Eriksson et al. } \\
\text { (13) } 1988\end{array}$ & & & & & & & & & & & & & & & & & \\
\hline Case 1 & $\mathrm{~F}$ & & & & & $<3 \%$ & $<1$ & & $<1$ & & & + & & & & + & \\
\hline Case 2 & M & & & & & & & & & & & & & & & & \\
\hline $\begin{array}{l}\text { Treem et al. } \\
\text { (14) } 1988\end{array}$ & $\mathrm{~F}$ & + & + & $\begin{array}{c}- \\
\text { (small adipic) }\end{array}$ & & $0-2.2 \S$ & $<1$ & 5 & & + & + & + & 2.6 & $44(24)$ & & & + \\
\hline
\end{tabular}

$* \mathrm{~N}$ (normal control values) $=35.5 \pm 5.6 \mu \mathrm{mol} / \mathrm{L}$

$\dagger \mathrm{N}=35-75 \mu \mathrm{mol} / \mathrm{L}$

$\ddagger \mathrm{N}=20-80 \mu \mathrm{mol} / \mathrm{L}$

$\S \mathrm{N}=37-58 / 28-47 \mu \mathrm{mol} / \mathrm{L}$. 
Case 4. A 71/4-y-old girl was born uneventfully of healthy nonconsanguinous Mexican parents. An older brother died at age 6 of progressive congestive heart failure. A second 13-y-old brother suffers from chronic bronchiectasis without cardiac disease and has developmental delay and unusual facial features but normal chromosomes.

The proband was noted to have an anemia at $15 \mathrm{~d}$ of age. At $2 \mathrm{mo}$, she had anorexia and diaphoresis on feeding, and a heart murmur was detected. At $7 \mathrm{mo}$, the anemia was characterized as normochromic and normocytic with a low reticulocyte count (Table 2). Serum iron, total iron binding capacity, and ferritin were normal. Repeated work-ups for blood loss were negative. A bone marrow biopsy at 32 mo showed decreased iron stores, for which she was treated. A Hb electrophoresis at $54 / 12$ y was normal.

There was mild gross motor delay; she rolled over at 9 mo and walked at 18 mo. A chest x-ray and ECG at 19 mo were reportedly normal. From 3 y of age, she had progressive failure to thrive, anorexia, low energy, elevated respiratory rate, and occasional complaints of chest pain. An echocardiogram at 54/12 $y$ revealed mild cardiomegaly. At age 5 , she also suffered from multiple episodes of somnolence and vomiting at school that forced her to return home. She was admitted to the hospital at $6 \% 12$ y in severe congestive heart failure with mitral regurgitation. Echocardiography revealed a dilated cardiomyopathy involving both the left and the right side of the heart with poor contractility. An ECG revealed mild 1st degree heart block, biventricular hypertrophy, and peaked $\mathrm{T}$ waves. She also had generalized weakness with decreased muscle bulk and persistent anemia (hematocrit 30). Initial therapy included digoxin and furosemide. Metabolic investigations revealed very low serum carnitine concentrations with normal levels of short- and long-chain esterified acyl carnitines. CK was normal. Muscle biopsy showed type I fiber predominance, lipid storage, and subsarcolemmal aggregates of enlarged mitochondria containing lipid and dense matrix granules. On oral carnitine therapy, she had marked clinical and ECG improvement with concomitant reduction of cardiac chamber dimensions. Motor function also improved, although she has some residual weakness $(4 / 5)$ in the shoulder girdle after 5 mo of therapy. Her affect and school performance have improved dramatically and she is currently a top student.

\section{MATERIALS AND METHODS}

All studies on the patients were performed with prior informed parental consent and with the approval of the institutional review boards of the various universities and hospitals. Total and free carnitine concentrations in plasma, urine, and muscle were measured as described by McGarry and Foster (15) for cases 1 and 4. Urinary organic acids for case 1 were measured by Dr. Orville Mamer (McGill University, Montreal, Canada). Dicarboxylic acids were identified in the urine as the trimethylsilyl derivatives by gas-liquid chromatography and were confirmed by gas chromatography-mass spectroscopy. The urinary fractional excretion of carnitine was calculated on the basis of the ratio of the clearance of carnitine to the clearance of creatinine.

Muscle biopsy specimens were immediately frozen for histochemistry and for the measurements of carnitine and $\beta$-oxidation enzymes. Other portions were fixed for light and electron microscopy. All $\beta$-oxidation enzymes in muscle were assayed spectrophotometrically, as previously described by Trevisan et al. (16).

Fibroblasts from the patients and their parents (passage 6-14) and from six control subjects (passage 6-12) were plated onto $9.5 \mathrm{~cm}^{2}$ six-well plates (Gibco Laboratories, St. Lawrence, MA) and allowed to grow to confluence in RPMI 1640 medium (Gibco) supplemented with $10 \%$ FCS (medium total carnitine, $2 \mu \mathrm{mol} / \mathrm{L}$ ). The uptake of carnitine was investigated in cultured skin fibroblasts by the method of Treem et al. (14). Cell-bound radioactivity was determined in $800 \mu \mathrm{L}$ of the final fibroblast hydrolysate using Aquasol-2 with a counting efficiency of $60 \%$.
Cell protein was measured in the remaining $200 \mu \mathrm{L}$ of the hydrolysate for each individual plate by the method of Lowry et al. (17). All experiments were performed in duplicate and run in parallel with one or two control cultures. Reproducibility of results was confirmed by separate experiments with the same cell line. Specific uptake of radioactivity was used to calculate the rates of total carnitine uptake. Apparent Michaelis-Menten constants ( $\mathrm{Km}$ and $\mathrm{V}_{\max }$ values) were determined by linear regression analysis of Lineweaver-Burk plots.

Carnitine uptake studies were also performed in patients with other defects in fatty acid oxidation (e.g. carnitine palmitoyl transferase deficiency) as well as with secondary carnitine deficiency (e.g. methylmalonic aciduria) to confirm the specificity and sensitivity of our studies for a primary carnitine transporter defect.

\section{RESULTS}

Table 1 summarizes the major clinical and laboratory features of our four cases. Two children had affected siblings, but none of the families were consanguinous and the ethnic origins were varied. All had early age of onset varying from $1 \mathrm{mo}$ to $17 \mathrm{mo}$. The presenting features were cardiomyopathy in two cases, motor delay in one, and hypotonia in the fourth case. All four children had cardiomyopathy with markedly increased cardiac dimensions and three had strikingly peaked T waves on ECG. Motor weakness and delay with lipid storage myopathy were noted in three cases and two children had mild elevations of serum CK. Enzymes of $\beta$-oxidation in muscle were normal in the one child in whom they were measured. One child (patient 3 ) had documented and one (patient 4) had suspected decreased fasting ketogenesis, which probably predisposed them to episodes of hypoglycemic encephalopathy.

Three children had failure to thrive and anemia. Only one child had fixed cognitive delay. Decreased renal reabsorption of carnitine was found in the three children in whom it was measured. Abnormal dicarboxylic aciduria was not found in any of the three children in whom it was measured.

The concentrations of serum carnitine were very low in all four children before carnitine supplementation (Table 2), and were not completely normalized even with large-dose oral carnitine therapy. Both parents of patient 2 had low serum carnitine values although not nearly as low as their son's. Muscle carnitine values were 4 and $6 \%$ of normal in two children and remained low $(15 \%)$ in one child who underwent a repeat muscle biopsy months after carnitine therapy.

On the basis of clinical, echocardiographic, and ECG criteria, cardiac function improved dramatically in all four cases after therapy, and the improvement was notable even within 1 mo of therapy. For example, in patient 1, the left ventricular enddiastolic dimension had decreased from 205 to $163 \%$ predicted (normal, 100\%), the left ventricular end-systolic dimension had decreased from 237 to $174 \%$ predicted (normal, 100\%), and the ECG showed a dramatic change with an inversion of the formerly peaked $\mathrm{T}$ waves in the lateral precordial leads. Clinically, motor function was significantly improved in all four patients who had been weak before therapy. Two children showed significant improvement in affect and school performance after carnitine therapy. Three children had significant failure to thrive with a remarkable improvement after therapy. In contrast, there was variable improvement in the variegate anemia documented in three cases.

Carnitine uptake in fibroblasts from normal controls suggested the presence of a high-affinity, low-concentration, specific carrier-mediated transport process with an apparent $\mathrm{Km}$ of $5.5 \pm$ $0.58 \mu \mathrm{M}$ and a maximal velocity in rate of uptake of $3.4 \pm 0.36$ $\mathrm{pmol} / \mathrm{min} / \mathrm{mg}$ of protein (Fig. $2 A$ and $B$; Table 3 ). These findings are in reasonable agreement with previously reported values $(14$, 18). Similar values were obtained in one child with carnitine palmitoyl transferase deficiency $\left(\mathrm{Km}=5.0 \mu \mathrm{M} ; \mathrm{V}_{\max }=3.33\right.$ 
$\mathrm{pmol} / \mathrm{min} / \mathrm{mg})$ and in another with hyperinsulinism $(\mathrm{Km}=6.6$ $\mu \mathrm{M} ; \mathrm{V}_{\max }=3.00 \mathrm{pmol} / \mathrm{min} / \mathrm{mg}$ ). Treem et al. (14) also showed that children with secondary carnitine deficiency disorders due to medium-chain and long-chain acyl $\mathrm{CoA}$ dehydrogenase deficiencies had $\mathrm{Km}$ and $\mathrm{V}_{\max }$ values similar to those of controls.

In contrast, the fibroblasts from our four patients showed minimal or no uptake of carnitine throughout the entire range of physiologic concentrations of carnitine precluding the possibility of calculating $\mathrm{Km}$ and $\mathrm{V}_{\max }$ values (Fig. $2 A$ and $B$; Table 3 ). At a carnitine concentration of $5 \mu \mathrm{mol} / \mathrm{L}$, the mean rate of uptake in the four patients was $0.0432(2 \%)$ as compared with $1.955 \pm 0.440 \mathrm{pmol} / \mathrm{min} / \mathrm{mg}$ protein in the controls. Their parents, on the other hand, showed intermediate maximal rates of carnitine uptake ranging from 13 to $44 \%$ of control $V_{\max }$ values, whereas $\mathrm{Km}$ values were normal (Fig. $2 A$ and $B$; Table $3)$. At very high concentrations of carnitine $(10 \mathrm{mM})$, patients, parents, and controls had the same rate of carnitine uptake, reflecting a common low-affinity, high-concentration, nonspecific diffusion uptake.

\section{PREVIOUSLY REPORTED CASES}

If the diagnosis of primary systemic carnitine deficiency requires direct demonstration of a carnitine uptake defect, then only the case of Treem et al. (14) should be considered in addition to our patients. However, there are six other cases that warrant consideration on the basis of indirect evidence including: 1) very low serum and tissue carnitine concentrations, 2) cardiomyopathy, 3) a rapid and dramatic response to carnitine therapy or, if no carnitine was given, a positive family history of a similarly affected sibling with carnitine-responsive cardiomyopathy, and 4) absence of abnormal dicarboxylic aciduria, which is seen in patients with secondary deficiency due to defects in $\beta$-oxidation or a lack of repletion of carnitine tissue stores despite oral carnitine therapy, implying a transporter defect (Tables 4 and 5). Primary carnitine-responsive cardiomyopathy was also distinguished from cases of X-linked cardiomyopathy with neutropenia, short stature, abnormal carnitine metabolism, and dicarboxylic aciduria (22-24).

\section{DISCUSSION}

Our results confirm that these four children have primary carnitine deficiency. All had very low serum carnitine and three also had low concentrations of muscle carnitine. Impairment of fatty acid oxidation was suggested by deficient ketogenesis during fasting and by the accumulation of lipid in muscle. The tissues most severely affected, heart, muscle, liver, and kidneys, derive much of their energy from fatty acid oxidation, for which carnitine is essential. The normal actitivies of $\beta$-oxidation enzymes in the muscle of one patient and the absence of dicarboxylic aciduria in three patients indicate that carnitine deficiency in these children was not secondary to other defects of fatty acid oxidation known to be associated with secondary carnitine deficiency. The rapid and dramatic clinical improvement in cardiac function, strength, and growth also suggested that the defect was due to primary carnitine deficiency and not to other abnormalities of fatty acid oxidation. In patients with secondary carnitine deficiency, it is still controversial as to whether carnitine therapy is beneficial in the acute or chronic stages (6).

The studies of carnitine uptake in vitro support the concept that primary carnitine deficiency is due to a defect in the active transport of carnitine, as suggested by Treem et al. (14) and Eriksson et al. (13). Under normal conditions, the carnitine concentration in tissues other than brain is 20 - to 50 -fold higher than in plasma (6). Uptake therefore occurs across a large concentration gradient and is maintained by a transport system driven by a large sodium potential across the plasma membrane $(1,25)$. Because carnitine is not degraded in the body, the kidney is primarily responsible for controlling body stores and is capable of adjusting to wide variations in dietary carnitine because it has a threshold of $40 \mu \mathrm{mol} / \mathrm{L}$, which is identical to the normal serum concentration (26). Three patients in our series in whom urinary carnitine was measured showed decreased renal reabsorption, indicating a defect of carnitine transport in the kidney, as demonstrated in several literature cases $(13,14,21)$. Also, muscle carnitine did not return to normal in our patient 2 when plasma carnitine concentrations were raised, suggesting that transport may also be impaired in muscle, as suggested by Treem et al. (14). Muscle carnitine concentration in three of our patients, as well as in six other reported childhood cases, was below $5 \%$ of normal, and below $2 \%$ in six of them, indicating severe tissue depletion. Furthermore, in several literature cases in which the carnitine-deficient patients underwent second muscle biopsies, carnitine therapy also failed to normalize the carnitine concentrations in muscle $(14,20)$, although there may have been clinical improvement or decreased muscle lipid storage (Table 5).

Our in vitro fibroblast studies showed a defect in the specific high-affinity, low-concentration, carrier-mediated carnitine uptake mechanism. Other clinically affected tissues in our patients could have been depleted of carnitine because of the low serum carnitine concentrations, which, in turn, were due to decreased renal conservation. In this case, however, one would expect tissue concentrations to be corrected when serum carnitine concentration is restored to normal. Alternatively, some tissues may share with fibroblasts a defect in the specific plasma membrane carnitine transporter, which would explain why carnitine concentrations failed to increase after carnitine replacement therapy. The therapeutic effect of carnitine administration may then result from the flooding of the unaffected nonspecific-diffusion, lowaffinity, high-concentration uptake mechanism, thereby bypassing the specific carrier-mediated transporter.

In contrast to muscle, liver carnitine concentrations rose dramatically from 3.5 to $400 \%$ and from 5 to $55 \%$ of normal in two patients reported in the literature after oral supplementation (14, 19 ), suggesting that carnitine depletion in liver was due to low serum carnitine concentrations. Treem et al. (14) proposed that their patient had a defect in a plasma membrane carnitine carrier that normally is shared by muscle, kidney, and fibroblasts but not by liver. Our patient 2 suggests similar conclusions. Whether the severe cardiomyopathy is due to low serum carnitine or to a specific transporter defect is unclear because no patient has had repeat endocardial biopsies. Evidence for a specific transporter defect in muscle and heart could be provided by carnitine uptake studies in cultured skeletal or cardiac muscle from patients. The $\mathrm{Km}$ values for carnitine uptake in cultured human heart cells $(4.8 \pm 2.2 \mu \mathrm{M})(27)$ and muscle $(1.90 \pm 1.38 \mu \mathrm{M})(18)$ were similar to the $\mathrm{Km}$ observed by us in cultured fibroblasts $(6.0 \pm$ $0.66 \mu \mathrm{M})$ and very different from the $\mathrm{Km}$ values observed in human liver $(500 \mu \mathrm{M})(28)$ and brain $(>1000 \mu \mathrm{M})(28)$.

On review of the literature, the age of presentation was under $4 \mathrm{y}$ of age in seven cases and under 12 mo in three (Table 4). The presenting feature was cardiomyopathy in six cases and coma in two. Cardiomyopathy was present in all cases by definition. The response to carnitine was dramatic, specific, and evident within the 1 st mo of therapy. In our case 1 , the initiation of carnitine therapy made other medications, such as digoxin and diuretics, unnecessary. The characteristic peaked $\mathrm{T}$ waves on ECG also disappeared with therapy (cases 1, 2, and 4; ref. 20, 21).

Heart has a high concentration of carnitine and is critically dependent upon fatty acid oxidation as an energy source. In addition, carnitine plays an important role in trapping toxic long-chain acyl $\mathrm{CoA}$ metabolites that accumulate in ischemia and may promote sarcolemmal membrane damage and arrhythmias. It has been suggested that long-chain acyl CoA may deform cellular membranes and potentiate the toxic effects of hydroperoxides, high $\mathrm{Ca}^{2+}$ concentrations, or elevated temperatures on mitochondrial membranes, and that these toxic effects are delayed by carnitine (29-31). 
Weakness was present in most cases, but was surprisingly absent in one patient (20) despite a low muscle carnitine concentration of $1 \%$.

Coma was probably due to hypoglycemia which, in turn, may be explained by the inability to decrease glucose consumption in later stages of fasting when ketone bodies generated from hepatic fatty acid oxidation normally replace glucose as a source of energy. Cognitive delay and pyramidal signs in two cases (14, 19) could have been the consequences of hypoglycemic encephalopathy and cardiac or respiratory arrest.

Unusual and unexplained CNS signs occurred in case 1 of Tripp et al. (20), a 9-y-old child who began having syncopal episodes at age 8 and had bilateral extensor plantar responses and minimal athetoid movements. Similarly, patient 2 in our series, a 10 -y-old boy, had moderate mental retardation with no obvious predisposing factors on history. The significance of carnitine to CNS function or development cannot be accurately assessed at present other than as a key preventive agent against hypoxic-ischemic encephalopathy secondary to cardiomyopathy or hypoglycemic hypoketotic encephalopathy. It is, however, interesting to note that in cases 1 and 4 of our series and in the case of Waber et al. (21), a dramatic improvement in affect and cognitive performance was noted after carnitine therapy.

The importance of carnitine for the bowel, another tissue highly dependent on the oxidation of fatty acids, is raised by our patient 2, who had recurrent episodes of unexplained diarrhea and abdominal pains that resolved with carnitine therapy. None of the reported cases had this problem, but smooth muscle disorders (e.g. pyloric stenosis, recurrent stridor, and gastroesophageal reflux) were present in $3 / 4$ of the children in the family described by Tripp et al. (20).

An intriguing question is the possible role of carnitine deficiency in the variegate anemia noted in three of our patients and in three other reported cases. Some response to carnitine treatment was noted in the three patients in whom $\mathrm{Hb}$ was measured after carnitine administration. In our series, case 2 had a hypochromic anemia and case 4 had a normochromic normocytic anemia with a low reticulocyte count and normal serum iron. Both patients of Tripp et al. (20) had a mild anemia and one of them had a trial of iron therapy with no response. The patient of Waber et al. (21) had a $\mathrm{Hb}$ of $10.4 \mathrm{~g} / \mathrm{dL}$ with mild macrocytosis and normal serum ferritin, folate, $\mathrm{B}_{12}$, and bone marrow aspirate. A male sibling of this patient died at age 23 mo with cardiomyopathy and mild anemia unresponsvie to iron therapy. The role of carnitine in the RBC is not well understood, but it has been proposed that carnitine may protect the $\mathrm{RBC}$ from membrane damage by toxic fatty acyl CoA derivatives $(20,32)$ or that it may improve lipid metabolism in the RBC membrane (33).

Combining our four cases with the seven literature cases showed a nearly equal sex distribution ( 6 female; 5 male), a history of affected siblings in eight cases, and asymptomatic parents, suggesting an autosomal-recessive pattern of inheritance. Our finding that the $\mathrm{V}_{\max }$ in all seven parents in our series was decreased to the heterozygote range (13-44\% of control $V_{\max }$ values) further supports this inheritance pattern and indicates that even a residual uptake of $13 \%$ is sufficient for normal function. There was no consanguinity in the four families studied by us and the patients had diverse ethnic backgrounds, suggesting that the defect is genetically widely distributed. Compared with uptake studies, serum carnitine concentrations in the parents are not good indicators for a decreased plasma membrane carnitine transporter. For example, although both parents of case 2 had low serum carnitine concentrations, the father of case 1 had normal serum carnitine concentrations despite a similarly decreased in vitro uptake. The variable serum concentrations in the presumed heterozygote parents was also described in other families $(14,20)$. Therefore, serum carnitine concentrations in the parents are a useful and simple screen, but in vitro cultured fibroblast uptake studies provide more definitive evidence of heterozygosity. The normal $\mathrm{Km}$ values for carnitine substrate concentration and the reduced $V_{\max }$ values for carnitine uptake in heterozygote parents suggest the presence of a reduced number of normally functioning carnitine receptors, but this remains to be confirmed.

Primary systemic carnitine deficiency is a specific entity characterized by carnitine-responsive cardiomyopathy with or without weakness, hypoglycemic hypoketotic encephalopathy, failure to thrive, and anemia with low plasma and tissue concentrations of carnitine, lipid storage in muscle and liver, and severe renal leak of carnitine. Exclusion of other defects in fatty acid oxidation is essential. The importance of an accurate diagnosis of this potentially fatal entity lies in the eminently treatable nature of the disorder through lifelong oral carnitine supplementation. Carnitine uptake studies in cultured skin fibroblasts are important for diagnosis and screening of siblings and heterozygote parents. These studies are also useful in understanding pathogenesis and investigating the molecular basis of this disease. Given the frequent history of previously unexplained sibling deaths in these families, early identification of presymptomatic siblings with institution of carnitine supplementation may decrease immediate and long-term morbidity and mortality.

Note added in proof: After submission of our manuscript, we noted the publication by Eriksson et al. 1989 (Transport of carnitine into cells in hereditary carnitine deficiency. $J$ Inher Metab Dis 12:108-111) in which the workers directly demonstrated a defect in carrier-dependent carnitine transport in fibroblasts from the girl with the cardiomyopathy previously described in Ericksson et al. 1988 (Eur J Pediatr 147:662-663, cited as reference no. 13), thus further supporting our data and adding another literature case with confirmed skin fibroblast carnitine uptake defect.

Acknowledgments. The authors thank Dr. Charles A. Stanley, Children's Hospital of Philadelphia, for his valuable scientific advice. We also thank Ann Zaragoza for excellent word processing. The EMG and NCS for case 1 were performed by Dr. Dale Lange, Neurological Institute, New York.

\section{REFERENCES}

1. Bremer J 1983 Carnitine-metabolism and functions. Physiol Rev 63:14201480

2. Engel AG, Angelini C 1973 Carnitine deficiency of human skeletal muscle with associated lipid storage myopathy: a new syndrome. Science 179:899_ 902

3. Angelini C, Trevisan C, Isaya G, Pegolo G, Vergani L 1987 Clinical varieties of carnitine and carnitine palmitoyl transferase deficiency. Clin Biochem $20: 1-7$

4. DiMauro S 1979 Metabolic myopathies. In: Vinken PJ, Bruyn GW (eds) Handbook of Clinical Neurology, Vol 41, Diseases of Muscle, Part II. North Holland, New York, pp 175-234

5. Rebouche CJ, Engel AG 1983 Carnitine metabolism and deficiency syndromes. Mayo Clin Proc 58:533-540

6. Stanley CA 1987 New genetic defects in mitochondrial fatty acid oxidation and carnitine deficiency. Adv Pediatr 34:59-88

7. Coates PM, Hale DE, Stanley CA, Glasgow AM 1984 Systemic carnitine deficiency simulating Reye syndrome. [letter] J Pediatr 105(4):679

8. Hale DE, Cruse RP, Engel AG 1985 Familial systemic carnitine deficiency. Arch Neurol 42:1133

9. Turnbull DM, Bartlett K, Stevens DL, Alberti KG, Gibson GJ, Johnson MA McCulloch AJ Sherratt HS 1984 Short-chain acyl-CoA dehydrogenase deficiency associated with a lipid-storage myopathy and secondary carnitine deficiency. N Engl J Med 311:1232-1236

10. Trevisan CP, Reichmann H, De Vivo DC, DiMauro S 1985 Beta-oxidation enzymes in normal human muscle from a patient with an unusual form of myopathic carnitine deficiency. Muscle Nerve 8:672-675

11. Rebouche CJ, Engel AG 1980 In vitro analysis of hepatic carnitine biosynthesis in systemic carnitine deficiency. Clin Chim Acta 106:295-300

12. Rebouche CJ, Engel AG 1984 Kinetic compartmental analysis of carnitine metabolism in the human carnitine deficiency syndromes. Evidence for alterations in tissue carnitine transport. J Clin Invest 73:857-867

13. Eriksson BO, Lindstedt S, Nordin I 1988 Hereditary defect in carnitine membrane transport is expressed in skin fibroblast. Eur J Pediatr 147:662663

14. Treem WR, Stanley CA, Finegold DN, Hale DE, Coates PM 1988 Primary carnitine deficiency due to a failure of carnitine transport in kidney, muscle and fibroblasts. N Engl J Med 319(20):1331-1336 
15. McGarry JD, Foster DW 1976 An improved and simplified radioisotope assay for the determination of free and esterified carnitine. J Lipid Res 17:277281

16. Trevisan CP, Reichmann H, De Vivo DC, DiMauro S $1985 \beta$-Oxidation enzymes in normal human muscle and in muscle from a patient with an unusual form of myopathic carnitine deficiency. Muscle Nerve 8:672-675

17. Lowry OH, Rosebrough NJ, Farr AL, Randall RJ 1951 Protein measurement with the folin phenol reagent. J Biol Chem 193:265-275

18. Rebouche CJ, Engel AG 1982 Carnitine transport in cultured muscle cells and skin fibroblasts from patients with primary systemic carnitine deficiency. In Vitro 18(5):495-500

19. Chapoy PR, Angelini C, Brown WJ, Stiff JE, Shug AL, Cederbaum AM 1980 Systemic carnitine deficiency-A treatable inherited lipid-storage disease presenting as Reye's syndrome. N Engl J Med 303(24):1389-1394

20. Tripp ME, Katcher ML, Peters HA, Gilbert EF, Arya S, Hodach RJ, Shug AL 1981 Systemic carnitine deficiency presenting as familial endocardial fibroelastosis. A treatable cardiomyopathy. N Engl J Med 305(7):385-390

21. Waber LJ, Valle D, Neill C, DiMauro S, Shug A 1982 Carnitine deficiency presenting as familial cardiomyopathy: a treatable defect in carnitine transport. J Pediatr 101(5):700-705

22. Neustein HB, Lurie PR, Dahms B, Takahashi M 1979 An X-linked recessive cardiomyopathy with abnormal mitochondria. Pediatrics 64(1):24-29

23. Barth PG, Scholte HR, Berden JA, Van der Klei-Van Moorsel JM, LuytHouwen IEM, Van't Veer-Korthof ETH, Van der Harten JJ, Sobotka-
Plojhar MA 1983 An X-linked mitochondrial disease affecting cardiac Plojhar MA 1983 An X-linked mitochondrial disease affecting cardiac 24. Ino T, Sherwood WG, Cutz E, Benson LN, Rose V, Freedom RM 1988 Dilated cardiomyopathy with neutropenia, short stature, and abnormal carnitine metabolism. J Pediatr 113(3):511-514

25. Rebouche CJ, Mack DL 1984 Sodium gradient-stimulated transport of Lcarnitine into renal brush border membrane vesicles: kinetics, specificity, and regulation by dietary carnitine. Arch Biochem Biophys 235:393-402

26. Engel AG, Rebouche CJ, Wilson DM, Glasgow AM, Romshe CA, Cruse RP 1981 Primary systemic carnitine deficiency. II. Renal handling of carnitine. Neurology 31:819-825

27. Bahl JJ, Bressler R 1987 The pharmacology of carnitine. Annu Rev Pharmacol Toxicol 27:257-277

28. Bieber LL 1988 Carnitine. Ann Rev Biochem 57:261-283

29. Subramanian L, Plehn S, Noonan J, Schmidt M, Shug AL 1987 Free radicalmediated damage during myocardial ischemia and reperfusion and protection by carnitine esters. Z Kardiol 76(5):41-45

30. Mak IT, Kramer JH, Weglicki WB 1986 Potentiation of free radical-induced lipid peroxidative injury to sarcolemmal membranes by lipid amphiphiles. J Biol Chem 261(3): 1153-1157

31. Siliprandi N, DiLisa F, Pivetta A, Miotto G, Siliprandi D 1987 Transport and function of L-carnitine and L-propionylcarnitine. Relevance to some cardiomyopathies and cardiac ischemia. Z Kardiol Suppl 5:34-40

32. Gilbert EF 1985 Carnitine deficiency. Pathology 17:161-169

33. Vacha GM, Giorcelli G, Siliprandi N, Corsi M 1983 Favorable effects of Lcarnitine treatment on hypertriglyceridemia in hemodialysis patients: decisive role of low levels of HDL-cholesterol. Am J Clin Nutr 38:532-540 